\title{
Title: Conceptual Study to Establish Basic Principle of Flap Method of Plastic Surgery of Sushruta in Modern Pilonidal Sinus Surgery
}

\author{
Authors: Kavita M. Dabhade*1, Vd. Bhagyashri Sakharkar ${ }^{2}$ \\ 1. P.G.Scholar,
}

2. Asst. Professor and Guide

Department of Shalyatantra

Government Ayurved College and Hospital, Nagpur, Maharashtra.

*Corresponding Author: E-mail: kaudabhade00@gmail.com; Contact no.: 9730106454

\begin{abstract}
:
Flap Method is the base of Plastic and Reconstructive surgery. Flap is a unit of tissue which is lifted from donor site and moved to a recipient site with an intact blood supply. It is done to fill a defect such as wound resulting from injury or surgery when the remaining tissue is unable to support a graft. Flap Method is a sub-speciality of plastic and Reconstructive surgery. Various types of flaps are perfornegend the indications for them are even more diverse. ${ }^{1}$
\end{abstract}

Acharya Sushruta is the father of stirgery. First Nasal Reconstruction using a forehead flap was performed by Sushruta in India during 600 to 700 B.C. ${ }^{2}$ The basic principle during this surgery was Vascularisation.

This basic principle of vascularisation during flap method is used now-a-days in Limberg Rhomboid Flap surgery of Pilonidal Sinus. It describes a technique for closing a $60^{\circ}$ rhombus shaped defect with transposition of flap. It is the practical application of flap method in Rhinoplasty of Sushruta.

Keyword: Flap method of Sushruta, Pilonidal sinus, Limberg flap surgery, Rhinoplasty. 


\section{Introduction:}

\section{Definition of pionidal sinus:}

Pilonidal sinus is a sinus tract or a small channel, may originate from the source of infection and open to the surface of the skin. It is of infective origin and occurs in sacral region between the buttocks, umbilicus, axilla. Pilonidal means nest of hairs and is derived from the latin words for hairs "pilus" and nest "nidus". 3

It is common in hairdressers and jeep drivers. It is common in 20-30 years of age. It is common in males especially in hairy men. It is also called as jeep bottoms, driver bottoms, pilonidal cyst, pilonidal abscess, sacrococcygeal fistula.

\section{Commonest site:}

Inter buttock sacral region. Hai after penetrating the skin causes dermatitis, infection, pustules and sinus formation which again suck hairs further by negative pressure forming pus and granulation tissues leading into multiple primary and secondary sinuses.

Primary sinuses occur in the mid line. Secondary sinuses occur laterally i.e. paramedian. ${ }^{4}$

\section{Causes:}

Risk factors are obesity, family history, prolonged sitting, greater amounts of hairs, not enough exercise.

One proposed cause of pilonidal sinus is ingrown hairs. ${ }^{5}$ Excessive sitting is thought to predispose people to the condition, as sitting increase pressure on the coccygeal region. Trauma is not belived to cause a pilonidal cyst, however such an event may result in inflammation of an existing cyst. However, there are cases where can occur months after localised injury to the area. Some researchers have proposed that pilonidal cyst may be the result of a congenital pilonidal dimple. $^{6}$

Excessive sweating can also contribute to the cause of a pilonidal cyst. Moisture can fill a stretched hair follicle, which helps create a low oxygen environment that promote the growth of anaerobic bacteria, often found in pilonidal cyst. The presence of bacteria and low oxygen level hamper wound healing and exacerbate a forming pilonidal sinus. ${ }^{7}$

\section{Clinical features:}

1. Discharge - either serosanguinous or purulent.

2. Pain - throbbing and persistent type.

3. Tender swelling - seen just above the coccyx in the midline i.e. primary sinus or on either side of midline i.e. secondary sinus.

4. Tuft of hairs may be seen in the opening of the sinus.

\section{Signs and symptoms:}

1. Pain / discomfort or swelling above the anus or near the tailbone that comes and goes

2. Opaque yellow or bloody discharge from the tailbone area.

3. Unexpected moisture in the tailbone region.

4. Discomfort with sitting on the tailbone doing situps or riding a bike (any activities that roll over the tailbone area). ${ }^{8}$ 
5. Some peoples with a pilonidal cyst will be asymptomatic. ${ }^{9}$

\section{Treatment:}

Treatment may include antibiotic therapy, hot compresses and application of depilatory creams i.e. a cosmetic preparation used to remove hairs from the skin on body, cryosurgery, $\mathrm{Z}$ plasty procedure, lancing under local anaesthesia, vaccum assisted closure, excision with secondary healing, excision with primary closure, local flap surgery, Bascom procedure have been described.

In more severe cases, the cyst may need to be lanced or treated surgically. Lancing is performed using a local anaesthesia with healing time generally undar one week. ${ }^{10}$ Lancing is a minor surgical procedure of incision and drainage of pus from boil or cyst.it is done with th help of sterile sharp needle, pointe scalpelor a lancet.

The most conservative surgical treatment Bascon's Pit Picking procedure is a relatively simple outpatient opinion that can be performed in a physician's office, involves minimal pain and requires only a few days healing. ${ }^{11}$

The most common course for surgical treatment is for the cyst to be surgically excised along with the pilonidal tract. Post surgical wound packing may be necessary and packing typically must be replaced once daily for 4-8 weeks. In some cases, two years may be required for complete granulation to occur. Sometimes the cyst is resolved via surgical marsupialisation.

To overcome the long hospital stay and fast recovery a Limberg flap for saccrococcygeal pilonidal sinus is a safe and sound procedure.

\section{Different Types of Flap Method:}

A flap is any tissue that is transferred from one place to another while maintaining its own blood supply. The term flap originated in the $16^{\text {th }}$ century from the Dutch word 'Flappe' meaning something that hang broad and loose fastened only by one side. The history of flap surgery dates as far back as 600 B.C., when Sushrut Samhita described Nasal reconstruction (Nasasandhan) using a cheek flap. Sushrut also describes aurolpasty (Karnasandhan), cleft lip surgery (Osthasandhan). The origins of forehead Rhinoplasty may be traced back to approximately 1440 A.D. in India.

First Nasal Reconstruction using a orehead flap was performed by Sushruta India during 600 B.C. First English description of the Indian midline forehead Rhinoplasty was published in the Madras Gazette in 1793.

1. The Limberg Flap

2. The Dufourmental Flap

3. The Webster or $30^{0}$ Flap

4. One Vascular Pedicle Flap

5. An Interpolated Flap

6. A Rotation Flap

7. A Transposition Flap

8. An Advancement Flap

9. A Bi pedicle Flap with Incision Parallel to Advancement

10. A V-Y Advancement Flap ${ }^{12}$

\section{Limberg Flap Reconstruction:}

The Limberg Flap is conceptually the easiest of the three flaps to reconstruct i.e. from the Dufourmental flap and Webster or $30^{\circ}$ flap. The Limberg flap is a 
series of communicating equilateral triangles. All angles are $60^{\circ}$, which mean that every side of both the defect and the flap is equal in length. This orientation creates a flap that is the same size as the defect to be excised. Any flap angle other than $60^{\circ}$ theoretically involves either widening or compression of the flap. An elliptical defect at the donor site remains after the flap is rotated to fill the rhomboid defect. This defect can be closed primarily with appropriate undermining of the surrounding tissue. ${ }^{13}$

\section{Sushruta's Rhinoplasty (Nasasandhan):}

Sushruta in Sutrasthana described the procedure of Rhinoplasty in detail. The portion of the nose covered with leaf to measure. Then a piece of skin of required size is to be dissected from the forehead or cheeks and turned back to cover the nose, keeping a small pedicle attached to th cheek. The part of the nose to which th skin is to be attached should be made raw by cutting the nasal stump. Then place the skin on nose and stitch the two parts, keeping the properly elevated by inserting two tubes of Eranda in the position of the nostrils, so that the new nose gets proper shape. It should be sprinkled with Yastimadhu powder and raktachandan. Finally covered with cotton and sesame oil (Til Tail) should be constantly applied. This procedure is still famous in modern surgery as Indian method of Rhinoplasty. ${ }^{14}$

The concept or principle of Sushruta behind this procedure was Vascularisation. As he stated that the flap must be "jivita", means it must have its own blood supply so that it will not depend on recipient. ${ }^{15}$

\section{Discussions:}

Plastic surgery has become increasingly common today for a variety of reasons. Plastic surgery includes number of different procedures that usually involves the skin. Today increasing trend of plastic surgery is leaning towards the cosmetic surgery. In modern flap method is used in different diseases like pilonidal sinus, lupus, basal cell carcinoma, cell neoplasm, etc. Basic principle of flap method is vascularisation. Acharya Sushruta in sutrasthan adhaya 16. Karnavyadhbandhavidhi described the nasal reconstruction surgery with the help of flap method with the basic principle of vascularisation. So it is clear that the base of todays plastic surgery has its origin from ancient times i.e. Sushrut Samhita.

\section{Conclusion:}

Results for Rhomboid excision and Limberg flap closure in the treatment of sacrococcygeal Pilonidal sinus, especially in recurrent cases and in patients with extensive involvement. Low recurrence rates, shorter hospital stay, time off from work may outweigh the disadvantages related to unfavourable cosmetic appearance. This flap surgery has its base principle of Vascularisation which is the concept from Shuhruta's Rhinoplasty. As Sushruta used the forehead or cheek flap for nasal reconstruction, same flap method is used in pilonial sinus surgery. Hence we can prove that, today's cosmetic and reconstruction surgery is the practical approach of the concepts from Ayurvedic samhitas i.e. ancient literature, and it's one of the example is flap method in pilonidal sinus surgery. 


\section{References:}

1. Khanna A; Rambeau, JL(March 2011) "pilonidal disease" clinics in colon and rectal surgery. 24(1):46-

53. PMC 3140333, PMID

22379405

https://www.ncbi.nih.gov/pmc/artic les/PMC3140333

2. James, William D,; Berger, Timothy;Elston, Dirk(2015). Andrew's Diseases of the Skin EBook: Clinical Dermatology. Elsevier Health Sciences. p.675. https://www.elsevier.com/books/an drews-diseases-of-theskin/james/978-0-323-31967-6

3. "Pilonidal cyst :Definition". Mayo Clinic. December 5, 2012. Retrived February 8, 2013.

https://en.wikipedia.org/wiki/piloni dal_disease

4. Shriram Bhat, SRB'S Clinical Methods in Surgery Jaypee Brothers Medical Publishers (P) Ltd. $2^{\text {nd }}$ edition 2015, page no.577

5. "Pilonidal cyst :Definition". Mayo Clinic. December 5, 2012. Retrived February 8, 2013. https://en.wikipedia.org/wiki/piloni dal_disease

6. Da Shiva JH(2000). Pilonidal cyst: cause and treatment. Dis. Colon Rectum. 43(8):1146-56 https://www.ncbi.nlm.nih.gov/pub $\underline{\text { med/10950015 }}$

7. Bascom, John; Bascom, Thomas (October 2002). "Failed Pilonidal Surgery". Archives of Surgery. 137(10):1146-50 https://ipfs.io/ipfs/.../wiki/Pilonidal cyst.html
8. Sternberg, Jeffrey. "What is Pilonidal Disease". Retrieved November 14, 2014. https://en.wikipedia.org/wiki/Piloni dal_disease

9. Doerr, Steven. "Pilonidal cyst". eMedicineHealth. P.1. Retrived February $\quad 8,2013$. https://www.revolvy.com/main/ind ex.php?s=Pilonidal+cyst

10. "Pilonidal Sinus Disease" www.worldwidewounds.com.

Retrieved 2016-05-22. https://en.wikipedia.org/wiki/Piloni dal_disease

11. Colov, Emilie Palmgrren; Bertelsen, Claus Anders (2011-1201). "Short Convalescence and minimal pain after out-patient Bascom's pit pick operation". Danish Medical Bulletin.58(12): A4348.

https://en.wikipedia.org/wiki/Piloni dal_disease

12. Boston: Little Brown and Co;1986, Tissue Flap Clssification: Classification and Principles of Flap

https://emedicine.medscape.com/ar ticle/1284474-overview

Limberg Flap for Saccrococcygeal Pilonidal Sinus a Safe and Sound Procedure.

https://www.ncbi.nlm.nih.gov/pmc/ articles/PMC4449468/

13. Dr.Anantram

Sharma,Sushrutsamhita Sutrasthan adhaya 16. Karnavyadhbandhavidhi, Chaukhamba Subharati Prakashan Varanasi, edition 2012, page no. 141.

14. Sri Dalhanachsarya, Sushrutasamhita of Sushruta with 
the Nibandhasangraha

Commentary, Sutrasthan adhaya 16 Karnavyadhbandhavidhi,

Chaukhamba Subharati Prakashan Varanasi, edition 2014, page no.78.

\section{Pictures:}

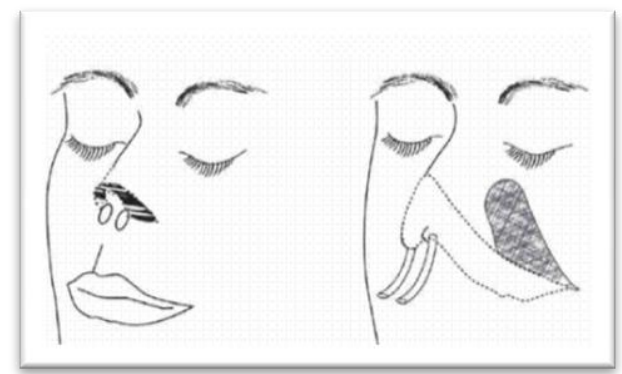

Fig: Plastic Repair of Nose described by Sushruta

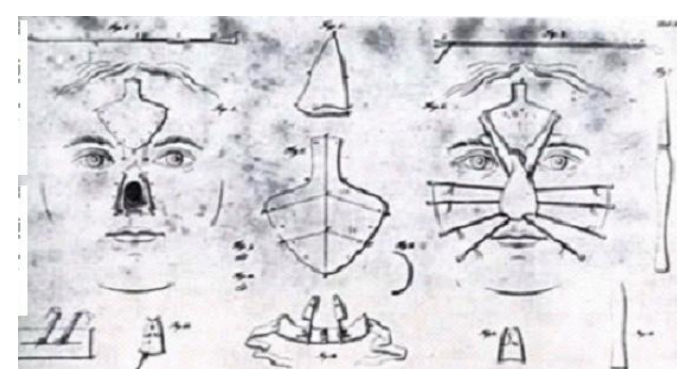

Fig: Indian Rhinoplasty

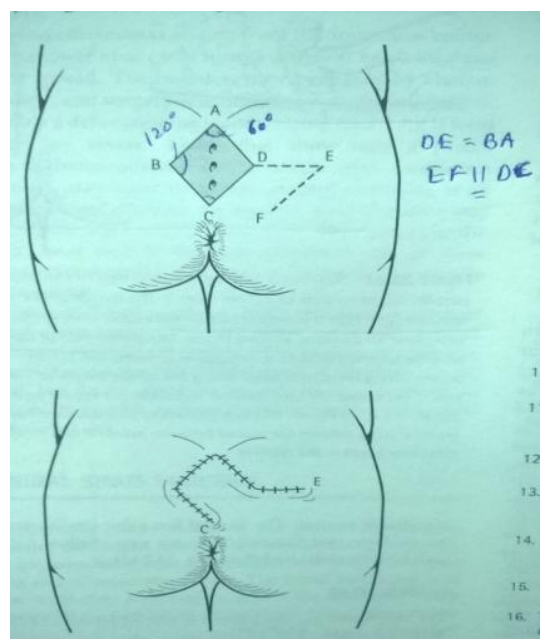

Fig: Limberg Flap Method for pilonidal sinus, markings for incision

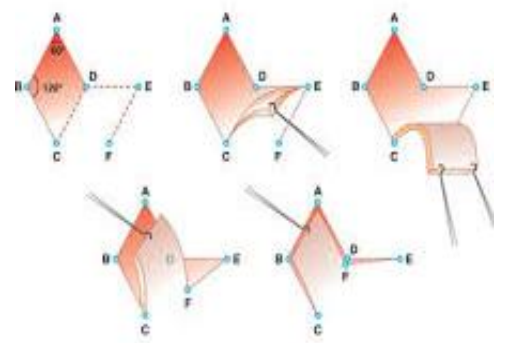

Fig: Limberg Flap Method(Incision)

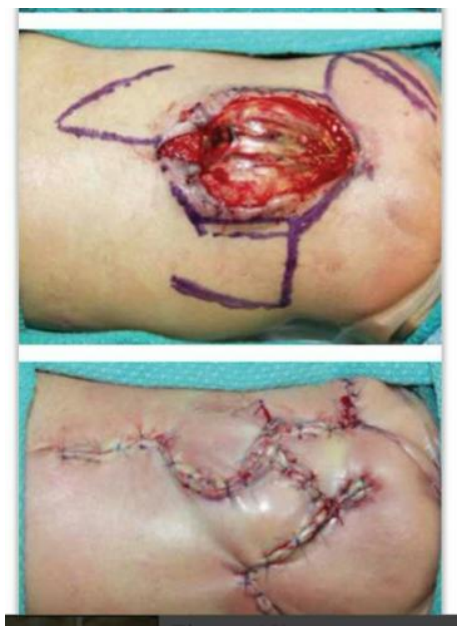

ig: Limberg Flap Method

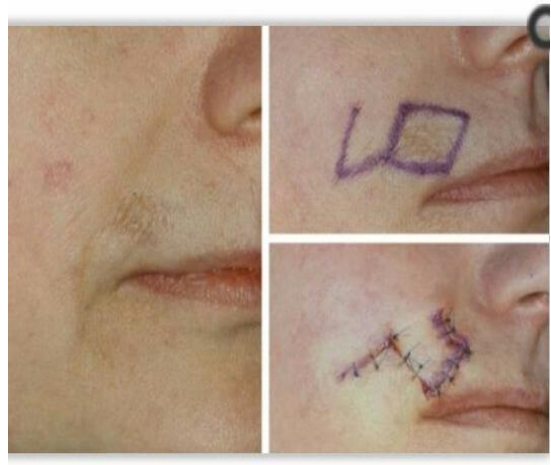

Fig: Lupus- Right upper lip 


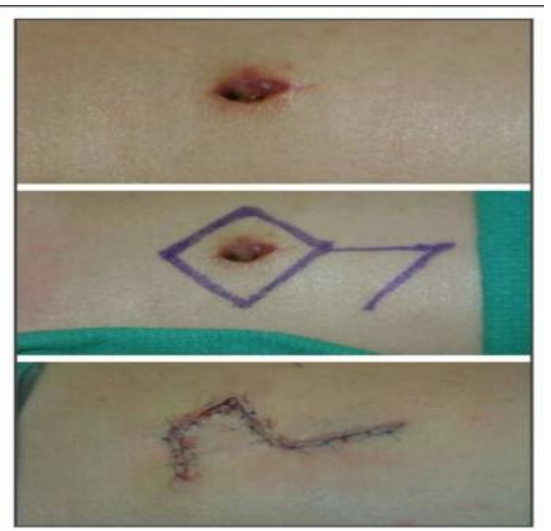

Fig: High grade, undifferentiated, small round cell neoplasm incompletely excised

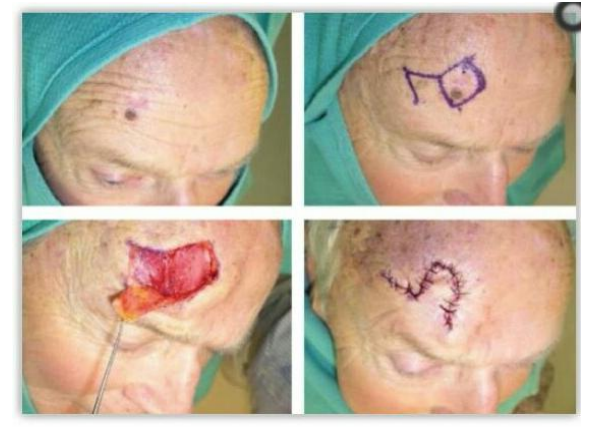

Fig: Basal cell carcinoma of the Forehead

\section{Cite article:}

Conceptual Study to Establish Basic Principle of Flap Method of Plastic Surgery of Sushruta in Modern Pilonidal Sinus Surgery

Kavita M. Dabhade, Bhagyashri Sakharkar

Ayurlog: National Journal of Research in Ayurved Science- 2018; (6)(4): 1-7 